\title{
Effects of integrated conservation-development projects on unauthorized resource use in Volcanoes National Park, Rwanda: a mixed-methods spatio-temporal approach
}

\author{
Katie P. Bernhard, Thomas E. L. Smith, Edmin Sabuhoro \\ Elias Nyandwi and Ian E. Munanura
}

\begin{abstract}
This study supplements spatial panel econometrics techniques with qualitative GIS to analyse spatio-temporal changes in the distribution of integrated conservation-development projects relative to poaching activity and unauthorized resource use in Volcanoes National Park, Rwanda. Cluster and spatial regression analyses were performed on data from ranger monitoring containing $>35,000$ combined observations of illegal activities in Volcanoes National Park, against tourism revenue sharing and conservation NGO funding data for 2006-2015. Results were enriched with qualitative GIS analysis from key informant interviews. We found a statistically significant negative linear effect of overall integrated conservationdevelopment investments on unauthorized resource use in Volcanoes National Park. However, individually, funding from Rwanda's tourism revenue sharing policy did not have an effect in contrast to the significant negative effect of conservation NGO funding. In another contrast between NGO funding and tourism revenue sharing funding, spatial analysis revealed significant gaps in revenue sharing funding relative to the hotspots of illegal activities, but these gaps were not present for NGO funding. Insight from qualitative GIS analysis suggests that incongruity in prioritization by decision makers at least partly explains the differences between the effects of revenue sharing and conservation NGO investment. Although the overall results are encouraging for integrated conservation-development projects, we recommend increased spatial alignment of project funding with clusters of illegal activities, which can make investment decision-making more data-driven and projects more effective for conservation.
\end{abstract}

KATIE P. BeRnhard (Corresponding author, (1) orcid.org/0000-0002-4121-7850) and Thомаs E. L. Sмiтн Department of Geography and Environment, London School of Economics and Political Science, London, UK

E-mail katiepbernhard@gmail.com

Edwin Sabuhoro Department of Recreation, Park and Tourism Management, College of Health and Human Development, Penn State University, State College, USA

Elias NYandwi GIS and RS Training and Research Centre, College of Science and Technology, University of Rwanda, Kigali, Rwanda

Ian E. Munanura Department of Forest Ecosystems and Society, College of Forestry, Oregon State University, Corvallis, USA

Received 9 January 2019. Revision requested 15 February 2019.

Accepted 11 June 2019. First published online 8 September 2020
Keywords Developing countries, integrated conservationdevelopment, livelihoods, local communities, qualitative GIS, Rwanda, spatial econometrics, tourism benefits

Supplementary material for this article is available at doi.org/10.1017/So030605319000735

\section{Introduction}

D oaching and unauthorized resource use, such as fuel- wood harvesting, present ongoing challenges for biodiversity conservation in the contiguous national parks at the intersection of the borders of Rwanda, Uganda and the Democratic Republic of the Congo, part of the Greater Virunga Transboundary Landscape. These problems persist despite policies and programmes designed to generate local community support for conservation. The stakes are high for both conservation and development: the Greater Virunga Transboundary Landscape is a biodiversity hotspot that provides the last remaining habitat for the mountain gorilla Gorilla beringei beringei and is also one of the most densely populated regions in Africa, with $600-700$ people per $\mathrm{km}^{2}$ (Martin et al., 2011; NISR, 2017).

Ecotourism provides a justification for protected areas in contexts where parks or reserves are collocated with poor communities that have high population densities, and where agriculture is a dominant economic sector and arable land is limited (Honey, 1999; Sabuhoro et al., 2017). In such areas, ongoing conservation challenges result from community dependence on resources in nearby protected areas for basic necessities such as fuelwood and water, or additional earnings from bushmeat poaching (Mackenzie et al., 2011; Munanura et al., 2016). Underpinning the case for ecotourism in the protected areas adjacent to these communities is the theory that it reduces poverty through economic opportunity. However, in practice, the benefits of ecotourism, which is considered mutually beneficial for both communities and conservation, have been slow to reach the most impoverished communities (Plumptre et al., 2004; Adiya et al., 2014). Furthermore, although ecotourism is growing, community-conservation conflict continues. Communities and individuals do not perceive benefits from conservation but have to bear its high costs, primarily from crop-using 
wildlife, which leads to persistent poverty and negative perceptions of protected areas (Twinamatsiko et al., 2014; Munanura et al., 2016, 2017; Sabuhoro et al., 2017).

To address livelihoods-related tensions between communities and protected areas, integrated conservation-development projects have been implemented across Africa since the 1980s (Garnett et al., 2007; Nielson \& Spenceley, 2011). The key theoretical link justifying these projects is that, because many of the illegal activities in protected areas are driven by basic livelihood needs, development projects that reduce this need will subsequently reduce pressure on protected areas (Munanura et al., 2017). These projects take many forms and are popular among conservation practitioners (Newmark \& Hough, 2000; Adams \& Infield, 2003). Government authorities have adopted integrated conservation-development projects both independently through tourism revenue sharing and in collaboration with conservation NGOs, with private sector initiatives emerging to fill needs not met by these programmes (Mukanjari et al., 2013). Such projects can include infrastructure, community enterprise, or household-level projects (Table 1). Tourism revenue sharing has been a key Rwandan government policy mechanism funding integrated conservation-development projects since 2005, to generate community buyin and disincentivize unauthorized extraction of park resources (Archabald \& Naughton-Treves, 2001; ORTPN, 2005; Mukanjari et al., 2013; Twinamatsiko et al., 2014; Munanura et al., 2016). In revenue sharing, a portion of revenue from hiking and gorilla permits or other ecotourism activities is redistributed to community development projects (Table 1). In Rwanda, as of 2018/2019, $10 \%$ of all tourism revenue is distributed to three national parks, with $40 \%$ to Volcanoes National Park. Project selection is highly bureaucratic, involving joint action committees and meetings between district, sector, and community level officials.

The primary objective of this study is to examine the effectiveness and limitations of community development projects in reducing poaching and unauthorized use of protected area resources. We distinguish between funding sources based on the authority administering funding: governmental vs nongovernmental, conservation-oriented entities that include conservation NGOs and private sector philanthropic ecotourism projects. We use GIS-based hotspot and spatial regression analysis to elucidate spatio-temporal patterns in the relationship between unauthorized use of park resources and community-development investment. We supplement the results of this analysis with interviews with key stakeholders.

In this study we ask how spatial techniques can help in investigating the role of community development investment in relieving ongoing conservation challenges in the Greater Virunga Landscape. We approach this with three subsidiary questions: (1) What are the sector-level spatial and spatio-temporal relationships between tourism revenue sharing and conservation $\mathrm{NGO} /$ private sector
TABLE 1 Number of integrated conservation-development project types funded by tourism revenue sharing, conservation NGOs and the private sector during 2006-2015 (source: Rwanda Development Board, pers. comm., 2018).

\begin{tabular}{lcc}
\hline & $\begin{array}{c}\text { Tourism } \\
\text { revenue } \\
\text { sharing }\end{array}$ & $\begin{array}{l}\text { Conservation } \\
\text { NGO/private } \\
\text { sector }\end{array}$ \\
Project type & 55 & 7 \\
\hline Agriculture/livestock & 1 & 11 \\
Agroforestry & 4 & 1 \\
Beekeeping & 9 & 10 \\
Bridge/road construction & & 2 \\
Cultural centre & 17 & 3 \\
Classroom/school/education & 2 & 1 \\
Handicrafts & 2 & 1 \\
Health post & 8 & 1 \\
Hotel & 6 & 3 \\
Housing & 4 & 2 \\
Latrines & & 3 \\
Power lines/energy & & 3 \\
Agricultural storage/processing & & 2 \\
$\quad$ facility (e.g. for grain) & & \\
Public/government office & & 295 \\
Savings \& credit cooperative & & \\
$\quad$ organizations (loan/finance) & & \\
Trench/wall/other structure to & 14 & \\
$\quad$ prevent wildlife crop use & & \\
Water & & \\
Total & 12 & \\
\hline
\end{tabular}

${ }^{1}$ See Supplementary Material 2 for further analysis regarding water projects.

investment and unauthorized resource use in Volcanoes National Park? (2) Where are the gaps in funding in communities outside the Park boundaries, and how do such gaps or hotspots of funding relate to illegal activities within the Park boundaries? (3) Do conservation NGO and private sector projects fill gaps in tourism revenue sharing, and do they perceive themselves as filling these gaps? How do decision makers prioritize funding distribution?

By linking spatial, quantitative and qualitative GIS analyses, we aim to contribute to scholarship in mixed-methods research (Knigge \& Cope, 2009). Our study thus contributes to cross-disciplinary collaboration in spatial modelling between ecological and social sciences (Addison et al., 2013). To understand the effect of integrated conservation-development projects on conservation outcomes, conservation management scholarship uses social science research methods to attempt to isolate the effect of these projects on socioeconomic conditions and forest dependency in communities adjacent to protected areas. As described by Mackenzie et al. (2011), this links stated demand for protected area resources with socio-economic factors such as population density, education and income (Plumptre et al., 2004; Munanura, 2013; Twinamatsiko et al., 2014; Maekwa et al., 2015). Our approach in this study uses actual incidents of forest dependency activity, rather than stated demand. Recent advances in data collection and software facilitate increasing use of 


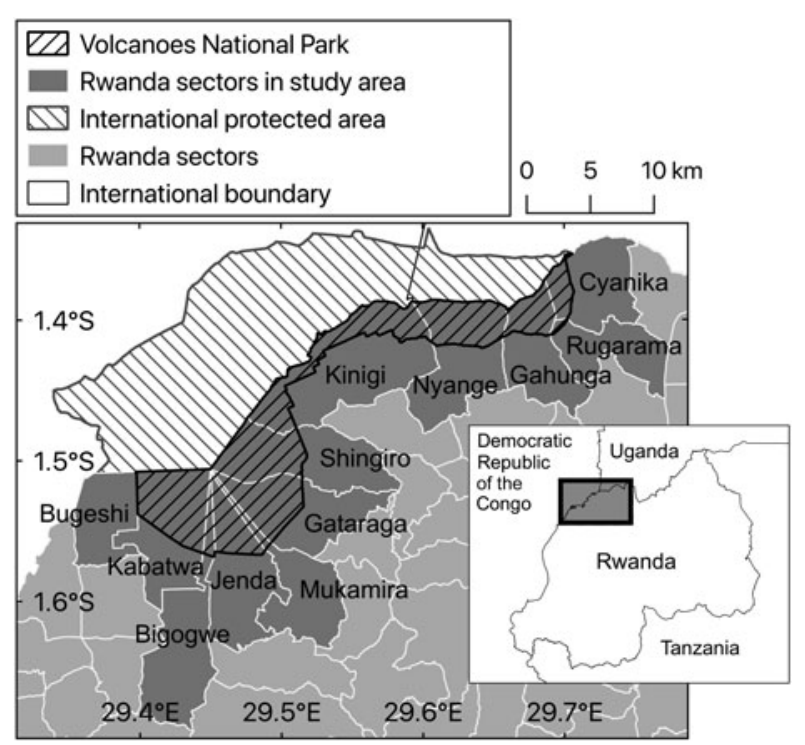

FIG. 1 Administrative sectors bordering Volcanoes National Park in Rwanda (data: UNEP-WCMC, 2014; GADM, 2018).

spatial data, including monitoring by rangers (Critchlow et al., 2017). Advances by Albers (2010), Plumptre et al. (2014) and Beale et al. (2014) adapted spatial modelling methods for unauthorized resource use. However, studies utilizing such data often focus on the ecological effects of human disturbance within protected areas, and few link observations of unauthorized resource use with socio-economic factors. However, we believe this is the first study within the integrated conservation-development literature that directly links the network of government, conservation NGO and private sector interventions to unauthorized resource use in protected areas.

\section{Study area}

The study was undertaken in Volcanoes National Park, Rwanda and surrounding landscape; the spatial distribution of integrated conservation-development projects bordering the Park is not well-defined relative to hotspots of illegal activity inside the Park, nor relative to each other. Although our study focuses on Rwanda specifically, Volcanoes National Park is part of the Greater Virunga Transboundary Landscape, which includes a total of 13 protected areas in Rwanda, Uganda and the Democratic Republic of the Congo (DRC; Fig. 1). Since the inception of mountain gorilla tourism in the Virungas in 1979, the Landscape has seen periods of volatility and revival (Nielsen \& Spenceley, 2011). In the 1990s, mountain gorilla conservation was affected by civil wars in Rwanda and Uganda, the 1994 genocide against the Tutsi in Rwanda, and ongoing conflict in eastern DRC (Martin et al., 2011). The combined efforts of law enforcement, monitoring, community conservation and tourism development have led to stabilization of mountain gorilla populations (Rainer, 2013; Munanura et al., 2016).

\section{Methods}

\section{Data collection and organization}

Secondary data Two main secondary data types were utilized in spatial and regression analyses: investment outside Volcanoes National Park, and illegal activities inside the Park. Firstly, community development investment data was acquired, including a revenue sharing dataset and a separate dataset for projects funded by conservation NGOs and private sector ecotourism partners (Sabuhoro et al., 2017; Community Conservation Warden, Volcanoes National Park, pers. comm., 2018). The revenue sharing data includes observations of projects funded annually in each Rwandan sector during 2006-2015 and funds allocated to each project. There are 134 projects in the dataset for the 12 sectors bordering Volcanoes National Park, including infrastructure projects and projects proposed by cooperatives (Table 1). The separate dataset for conservation $\mathrm{NGO}$ /private sector community development projects contains 297 observations of projects, including latitude/longitude coordinates, for 2006-2015 (Sabuhoro et al., 2017). Interventions include those funded by organizations such as the International Gorilla Conservation Programme and Rwanda Eco-Tours (Table 1). We sorted projects with multiple funding sources into the category that provided majority funding.

Secondly, ranger patrol logs were acquired for Volcanoes National Park (Research and Monitoring Warden, Volcanoes National Park, pers. comm., 2018). This rangerbased monitoring data includes latitude/longitude coordinates and descriptions of illegal activity recorded on routine patrols during 2006-2015. On such patrols, rangers travel in small groups along predetermined routes, marking observation coordinates, time, descriptions and counts (e.g. two snares, four water collectors). The cleaned ranger patrol data includes 14,720 observations for a total of 35,116 illegal activities recorded during 2006-2015 in Volcanoes National Park, excluding 2009 because of data loss caused by a change in data management software in that year (Fig. 2, Supplementary Table 1, Supplementary Material 1).

Biases in secondary data Ranger-based monitoring data is vulnerable to biases from data collectors (rangers) and data generators (individuals extracting resources; Keane et al., 2011). As a law enforcement tool intended for deterrence, ranger patrols involve non-random spatial patterns of patrolling and thus introduce sampling bias. Increasing effort or coverage can reduce total illegal activities through deterrence, but also increase the proportion of total activities detected (Keane et al., 2011; Moore et al., 2018). Selection of patrol areas and subsequent effort may be based on known problems with illegal activity (Albers, 2010; Critchlow et al., 2017). 

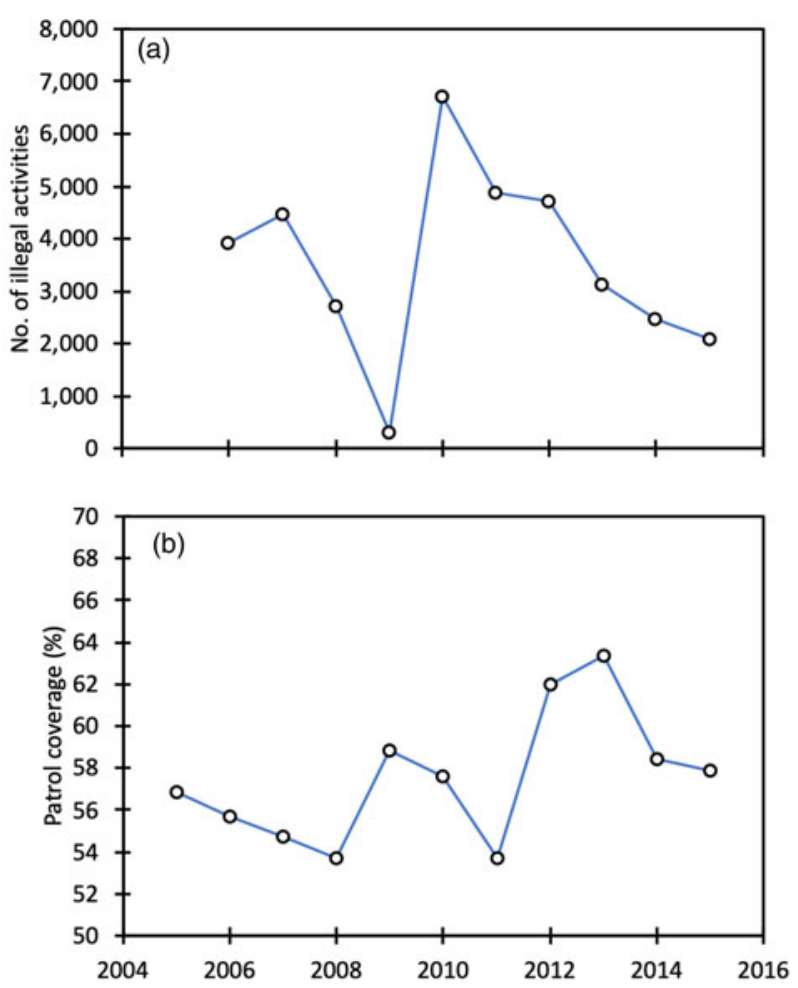

FIG. 2 (a) Total number of illegal activities recorded, and (b) patrol coverage as a per cent of area covered annually in Volcanoes National Park (Fig. 1) during 2005-2015 (data: Research and Monitoring Warden, Volcanoes National Park, pers. comm., 2018).

Raw, uncorrected data has been used in the literature, but common methods to address bias in ranger-based monitoring data include weighting encounters using catch per unit effort $(\delta)$, incorporating a detectability coefficient, and new methods in Bayesian hierarchical modelling (Hilborn et al., 2006; Watson et al., 2013; Beale et al., 2014; Critchlow et al., 2017). We calculated weighted catch per unit effort using annual number of rangers present on patrols and a proportional measure of annual patrol coverage (Keane, 2011; Research and Monitoring Warden, Volcanoes National Park, pers. comm., 2018; Law Enforcement Warden, Volcanoes National Park, pers. comm., 2018). For further details regarding the data used for these calculations, see Supplementary Material 1.

We used the following equations (Keane et al., 2011):

$$
\begin{aligned}
\delta_{s t} & =\text { Encounters }_{s t} \times \text { Effort }_{t} \delta_{s t} \\
& =\text { Encounters }_{s t} \times \text { Effort }_{t} \\
\text { Effort }_{t} & =\text { Rangers }_{t} \times \text { Coverage }_{t} \text { Effort }_{t} \\
& =\text { Ranger }_{t} \times \text { Coverage }_{t}
\end{aligned}
$$

where $\delta$ is weighted detected encounters in sector $s$ for year $t$. Encounters is raw encounters in sector $s$ for year $t$. Effort is proxied by annual number of rangers participating in routine patrols, and Coverage is the proportion of Park area covered by patrols in year $t$, the latter determined using ArcGIS 10.6 (Esri, Redlands, USA). This assumes a directly proportional relationship between detection, abundance of incidents and effort exerted. Although this calculation is coarse, this approximate correction is preferred over none (Keane et al., 2011). There are many factors contributing to effort and coverage, such as daily fluctuation in the number of patrollers, individual abilities, perceived severity of illegal activity in a given area, length of patrol, and weather conditions (Plumptre et al., 2014).

Primary data collection for qualitative GIS Key informant interviews were guided by results of quantitative analysis of secondary data, in particular to ascertain the prioritization driving investment decision-making by different stakeholders. Numerical weighting of an interviewee's priority sectors produced attributes that were spatially joined to administrative boundaries. Eleven key informants with knowledge of funding prioritization were interviewed in June and July 2018 based on their positions as project decision makers in the government, conservation NGO or private sectors. This sample includes a variety of perspectives on investment decision-making, providing supplementary information to enrich and answer questions prompted by results of spatial and quantitative analysis (Knigge \& Cope, 2009; Supplementary Table 3).

\section{Data analysis}

Spatial statistics Firstly, using kernel density estimation for point pattern analysis, we produced raster-based maps visualizing regions with high densities of unauthorized resource use in Volcanoes National Park. Kernel density estimates using a quartic biweight kernel for illegal activity were overlain with proportional indicators of tourism revenue sharing investment for the respective year (Fig. 3), and total conservation $\mathrm{NGO}$ /private sector investment for the 2011-2015 period (Fig. 4; Silverman, 1986).

Following this exploratory spatial data analysis, we then tested the statistical significance of the relation of clusters to each other using a bivariate local indicator of spatial association, the bivariate local Moran's I statistic. A bivariate local Moran's I value of zero indicates random sorting of one variable relative to the other, with -1 signifying dispersion and 1 signifying clustering. This statistic is mathematically identical to spatial autoregression of $y(W y)$ on $x$. A cautionary approach is suggested by Lee (2001) and Anselin (2018) when interpreting bivariate local Moran's I, analysing $X$ and $Y$ at location $A$. The bivariate statistic does not consider the spatial relationship between the value of $X$ at location $A$ and the value of $Y$ at location $A$, only the value 

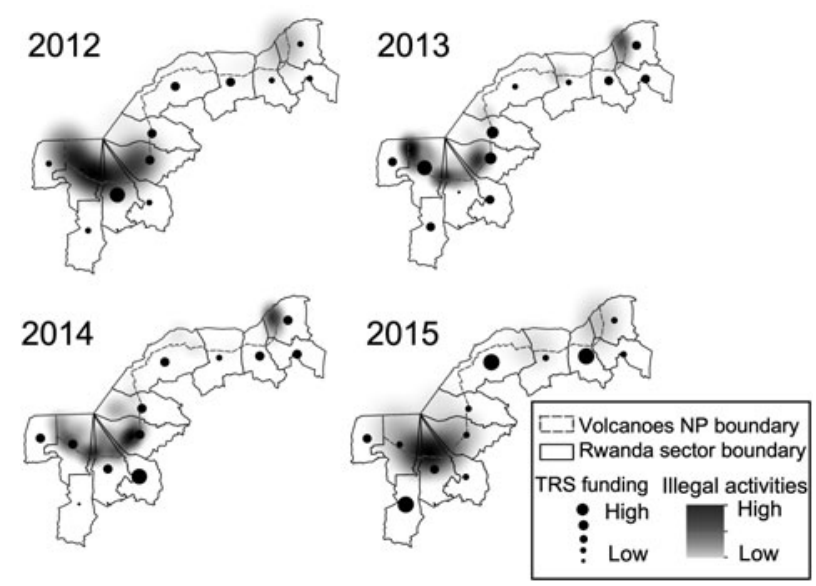

FIG. 3 Kernel density estimation of illegal activities in Volcanoes National Park for 2012-2015, clipped to Park boundaries (radius $10 \mathrm{~m}$ ) overlain with a proportional indicator (circle indicator in each sector) of the tourism revenue sharing (TRSo funding distributed to each sector annually. Point-level data were not available for visualization of revenue-sharing distribution at a finer spatial scale (data: Research and Monitoring Warden, Volcanoes National Park, pers. comm., 2018).

of $X$ at location $A$ and the neighbourhood's value of $Y$, as the equation uses a spatial lag of $Y$ (queen contiguity). The bivariate local Moran's $I$ is given by:

$$
I_{B}=\frac{\sum_{i}\left(\Sigma_{j} W_{i j} y_{j} \times x_{i}\right)}{\sum_{i} x_{1}^{2}}
$$

(Anselin, 2018), where $x_{i}$ is revenue sharing at sector $i . W_{i j} y_{j}$ is the spatial lag of $y$, which is the illegal activities count in sector $j$, using a row-normalized queen contiguity weight, selected to accommodate the sector-level scale. The weights structure is:

$$
W_{i j}=\frac{w_{i j}}{\sum_{j} w_{i j}}
$$

(Lee, 2001), with $w_{i j}=1$ indicating contiguity between sectors $i$ and $j$. This spatial weight essentially averages the values of illegal activities for all sectors bordering the sector of interest. The bivariate local indicator of spatial association cluster and significance maps (Supplementary Fig. 4) show areas of high-low and low-high, which respectively indicate sectors receiving high revenue sharing in a cluster of low illegal activities, or low revenue sharing in a cluster of high illegal activities. This reveals sectors in which the prioritization of funding is not aligned with levels of illegal activity occurring in that neighbourhood of sectors. The overall significance threshold for Moran's I outputs in this study was $10 \%$.

Econometric models Two models were constructed for panel regression analysis: (a) spatial lag of $x$ model (Equation 5, below) and (b) site-demeaned fixed effects (Equation 6,

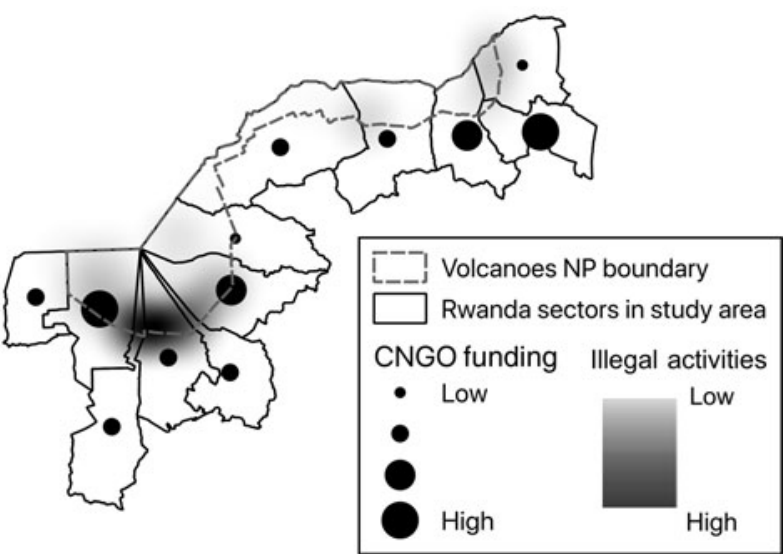

FIG. 4 Kernel density estimation of illegal activities in Volcanoes National Park (radius $10 \mathrm{~m}$ ) in 2015 clipped to Park boundaries and overlain with a proportional indicator (circle indicator in each sector) of the conservation $\mathrm{NGO}$ /private sector project funding (CNGO funding) distributed to each sector during 2011-2015 (data: Research and Monitoring Warden, Volcanoes National Park, pers. comm., 2018).

below). Unauthorized resource use is a function of local, sector, national, transboundary regional and global factors, both time-invariant and time-variant (Hsiang \& Sekar, 2016). Panel econometrics facilitates site-demeaned fixed-effects regression, accounting for time-invariant unobservables such as sectorlevel ecological and socio-economic conditions affecting unauthorized resource use, and time-variant factors are addressed in spatial lag of $x$ regression. The two model types thus facilitate corroboration of results. Time variant factors addressed by spatial lag of $x$ regression at sector level include integrated conservation-development project investment, population density, movement of poachers between sites, and local conditions such as agricultural yields and precipitation. National factors include tourism influx, which affects revenue sharing investment, and overall national economic and political stability. Armed conflict in the transboundary system can affect demand for protected area resources, as can global economic conditions (Rainer, 2013). Time-invariant factors addressed by fixed effects include the proportion of a sector that is within protected area boundaries and areas where tourist presence is highest, which has a consistent annual deterrence effect. Removing site-level means, site-demeaned fixed effects nonparametrically holds these factors constant.

Although identifying clusters of funding and unauthorized resource use across the study area is a standalone interest of this study, isolating spatial autocorrelation was necessary prior to spatial lag of $x$ regression, to eliminate spatial bias in the regression (Anselin, 1988). The same Moran's I statistics can be used for both identifying clusters and for determining spatial autocorrelation. For example, 
sectors of higher human population density, which are also temporally variant, may report more unauthorized resource use encounters. But sectors of high and low human population density are also clustered (univariate local Moran's I: 0.4526; Supplementary Figs $5 \& 6$ ); the top quantiles of population density are in the south-west and easternmost sectors, with low density in central sectors. In this example, the regression coefficient for population density (explanatory) on unauthorized resource use (response) would be inflated without spatial weighting.

We estimated the relationship between illegal activities and community development investment by the following multivariate linear spatial lag of $x$ model:

$$
\begin{aligned}
\delta_{s t}= & \alpha+\beta_{1} X_{s t}+\beta_{2} W X_{s t}+\beta_{3} t_{r s}+\beta_{4} W_{t r s_{s t}} \\
& +\beta_{5} n g o_{s t}+\beta_{6} W n g o_{s t}+\varepsilon_{s t}
\end{aligned}
$$

where $\delta_{s t}$ is the value of illegal activities corrected for catch per unit effort in year $t$ and sector $s$; $X_{s t}$ is a vector of controls, such as annual sector human population density and precipitation and area of a sector within the Park boundaries, calculated with $\operatorname{ArcGIS}$ (Goodman et al., 2019); $\operatorname{trs}_{s t}$ is revenue sharing funds distributed to sector $s$ for year $t ; n g o_{s t}$ is the conservation NGO and private sector investment in sector $s$ for year $t$; and $W$ indicates spatially lagged variables. We tested spatial autocorrelation using univariate local Moran's $I$ and constructed lags using queen contiguity matrices for those exhibiting Moran's $I>0.4000$ (Supplementary Figs $4 \& 5$ ). The model was adjusted as needed to account for collinearity, determined by Pearson's correlation coefficient, and a stepwise procedure was used to ensure robustness and model fit.

Next, using site-demeaned fixed effects (selected over random effects using a Hausman test, $\mathrm{P}=0.004$ ), we estimated the following model:

$$
\delta_{t}=\mu_{s}+\gamma_{t}+\rho_{s t}+\varepsilon_{s t}
$$

where $\delta t$ is corrected illegal activities in year $t, \mu_{s}$ is the sector fixed effect, $\gamma_{t}$ is time (year), $\rho_{s t}$ is a vector of time-varying interest and control variables including $t r s_{s t}$ and $n g o_{s t}$, and $\varepsilon_{s t}$ denotes the error term (i.e. unobservables across sectors). With clustered standard errors and lack of multicollinearity verified using Pearson's $r$, ordinary least squares estimation was used (Stock \& Watson, 2006). Omitted variable bias is possible in spatial lag of $x$ modelling (Equation 5 ) but the fixed effects (Equation 6) provides verification.

As policy or other country-level change impacts the spatial distribution of illegal activities at regional (country) and local (sector) levels, standard errors are unlikely to be independent across observations. Throughout the analysis, we cluster standard errors to sector to ensure robustness to heteroscedasticity (Stock \& Watson, 2006; Hsiang \& Sekar, 2016).
Spatial regression is sensitive to numerous technicalities, such as the endogenous structure of queen contiguity weights (Anselin, 1988; Gibbons \& Overman, 2012). This analysis is also sensitive to issues of scale such as the ecological fallacy (Moulton, 1990; Briant et al., 2010). Lastly, analyses presented in this study do not isolate causality in the relationship between integrated conservation-development project investments and unauthorized resource use in Volcanoes National Park but, taken together, these analyses establish spatial correlations between investments and unauthorized resource use.

\section{Results}

\section{Spatial statistical results}

Analysis of the mapping outputs in Figs 3 \& 4 reveals that although overall counts of illegal activities may have decreased during 2011-2015, this pattern is spatially inconsistent. For example, the Cyanika sector saw a relative increase in illegal activities whereas the southern sectors, including Kabatwa, Bigogwe, Jenda, Mukamira and Gataraga, remained consistent hotspots of illegal activity throughout the period.

In the bivariate local indicator of spatial association outputs presented in Supplementary Fig. 4, it is clear that although the overall clustering of development investment with illegal activities has declined over time (from 0.4165 in 2011 to 0.0059 in 2015), there were still sectors of statistically significant clustering and dispersion throughout the period. In 2015 the south-west sectors of Jenda and Mukamira exhibited a low-high bivariate local indicator of spatial association clustering significant at $0.01 \%$. These sectors thus exhibited low revenue sharing investment in a neighbourhood of sectors of high illegal activity for that year. The sectors with the most prevalent high-low and low-high relationships between revenue sharing and illegal activities were consistently Cyanika, Kabatwa, Bigogwe, Jenda, Mukamira and Gataraga. These simple correlations are not necessarily causal but illustrate spatial inconsistencies in the overall trends for 2011-2015. These trends are examined further below.

\section{Regression results}

For interpretation purposes, a negative coefficient signifies that a one-unit increase in that variable results in a decrease in the response variable, either raw illegal activities or catch of illegal activities per unit effort. A positive coefficient thus suggests that a one-unit increase in that variable increases illegal activities.

From the regression results in Table 2 there is a clear difference in the relationship between illegal activities and conservation $\mathrm{NGO}$ /private sector vs revenue sharing investment (column 5 vs column 6). Unexpectedly, in no 
regression specification did revenue sharing have a significant effect on illegal activities (the coefficient is insignificant but positive in all specifications). In contrast, conservation $\mathrm{NGO} /$ private sector project investments have a small negative linear effect on illegal activities (both corrected and raw) that is significant at least at $10 \%$ in all specifications. This includes specifications incorporating spatially lagged variables, which slightly reduce the effect of the investment on illegal activities (columns 3-5). The combined revenue sharing and conservation $\mathrm{NGO} /$ private sector variable also has a small but significant (at 10\%) negative effect on corrected illegal activities. This effect is smaller than that of conservation $\mathrm{NGO}$ /private sector, comparing columns 4 and 5 , presumably because of the addition of revenue sharing into the variable.

The controls have highly significant effects on illegal activities, particularly area of the sector within Park boundaries $(\mathrm{P}<\mathrm{0.01})$. However, precipitation, included to proxy agricultural yield differences, and population density lose their significance when accounting for spatial autocorrelation.

The results of spatial lag of $x$ regression are consistent with site-demeaned fixed effects (Table 3). The significance is reduced but still present for combined revenue sharing plus conservation $\mathrm{NGO}$ /private sector investments when time-variant controls are included in the specification (column 3). Furthermore, the sign of each interest variable's coefficient is consistent across models.

In summary, spatial regression indicates a small but significant negative linear relationship between total integrated conservation-development project investment and corrected illegal activities for 2006-2015. However, the nature and significance of this effect is different for tourism revenue sharing and conservation $\mathrm{NGO}$ /private sector investment. As is illustrated by Table 1 and the kernel density estimates in Figs 3 \& 4, revenue sharing and conservationNGO funding target different sectors, fund different projects, and are distributed based on a different set of priorities and interests.

\section{Integrating qualitative GIS}

Key informants were selected for interview based on these results (Supplementary Table 3 \& Supplementary Fig. 7) (Knigge \& Cope, 2009; Taylor, 2020). Interviewees with both tourism revenue sharing and conservation NGO/private sector interests indicated that, as the origin of many poachers, Kinigi is highly prioritized by all stakeholders. Poachers are known to move from Kinigi to other sectors to extract Park resources. As illustrated in the qualitative GIS (Fig. 5), Kinigi and Shingiro thus divert decision maker priority away from sectors where actual incidents are recorded. Averaged interviewee prioritization (Fig. 5a) aligns closely with poacher origins (Fig. 5b).
Figure 5 illustrates how stakeholder interests affect the spatial distribution of investment, providing one possible explanation for the inconsistent regression coefficients of tourism revenue sharing vs conservation NGO, and the high-low/low-high sectors in the bivariate local indicator of spatial association sectors. Although conservation NGO interviewees largely prioritize Kinigi and sectors where poachers originate, they also perceived their projects to be filling funding gaps created by the process of disbursement of revenue sharing funds (NGO4; Supplementary Table 3). If funding gaps that are being filled by NGOs are closer to actual incidents of illegal activities, as Fig. 4 illustrates, this could be one reason why conservation NGO funding was found to have a negative regression coefficient and tourism revenue sharing did not. Interviewees also cited the bureaucracies of revenue sharing and conflicting interests of stakeholders during project selection as impeding delivery of revenue sharing funding to areas where it was most needed. This also disperses the funding distribution ( $\mathrm{NGO}_{1}, \mathrm{VNP}_{3}$, VNP4; Supplementary Fig. 7).

These findings reaffirm the importance of following spatial and quantitative analysis with qualitative investigation. For example, from the spatial analysis alone, funding allotted to Kinigi could be imprecisely interpreted as disproportionate to its severity of unauthorized resource use. But through qualitative analysis, we found that the severity of unauthorized resource use was not the top priority for funding decision makers.

\section{Discussion}

Overall, spatial regression analysis provides evidence that total integrated conservation-development project investment had a small but significant negative linear effect on unauthorized resource use during 2006-2015. However, we also found spatial and temporal differences between investment sources, with conservation NGO funding, but not tourism revenue sharing, having a negative linear effect on unauthorized resource use. The lack of significance of revenue sharing compared to the conservation NGO variable is at least partly attributable to the smaller magnitude of funding from revenue sharing. However, the positive sign of the effect, particularly relative to conservation NGOs, warrants further discussion. Spatial inconsistencies in the distribution of revenue sharing across the sectors of Volcanoes National Park may impact its effect on unauthorized resource use. If these projects are intended to relieve pressure on protected area resources by providing alternatives for the poor, such as water tanks, employment alternatives or education, then projects should be targeted at areas that demonstrate high levels of the corresponding need in terms of high levels of unauthorized use of protected area resources (Munanura, 2013; Sabuhoro et al., 2017). As 
TABLE 2 Results of spatial lag of $x$ regression, with illegal activities as the response variable (Equation 5). Values are regression coefficients with cluster-robust standard errors in parentheses. Columns numbered 1-3 present the results with raw illegal activities as the response variable, and columns 4-7 use the illegal activities corrected using catch per unit effort (CPUE). Thus, these two sets of specifications using the different response variables facilitate comparison of the effect of tourism revenue sharing and conservation NGO and private sector funding when illegal activities are uncorrected versus when corrected using CPUE. Within these two sets, different specifications are presented to isolate the effects of tourism revenue sharing and conservation NGO and private sector funding as explanatory variables. For example, column 2 separates the effects of tourism revenue sharing and conservation NGO and private sector funding, whereas column 3 shows the effect of total combined investments. Columns 1, 2 and 4 also remove spatial lags for the controls, allowing comparison to columns 3 and $5-7$, which do include spatial lags in the controls. Tourism revenue sharing does not have a spatial lag because, as illustrated in Supplementary Fig. 5, it is not spatially clustered. Columns 5-7, which maintain the controls and relevant spatial lags while also using the CPUE-corrected response variable, are the primary specifications of interest. For each year there is one aggregated observation for each sector (12 per year). Thus for 10 years, $12 \times 10=120$. With the removal of $2009,120-12=108$. Therefore, the panel constructed has $\mathrm{n}=108$ observations.

\begin{tabular}{|c|c|c|c|c|c|c|c|c|}
\hline \multirow[b]{2}{*}{ Variable type } & \multirow[b]{2}{*}{ Variable description $^{1}$} & \multicolumn{3}{|c|}{$\begin{array}{l}\text { Response variable: } \\
\text { uncorrected, raw illegal activities }\end{array}$} & \multicolumn{4}{|c|}{$\begin{array}{l}\text { Response variable: } \\
\text { CPUE-corrected illegal activities }\end{array}$} \\
\hline & & 1 & 2 & 3 & 4 & 5 & 6 & 7 \\
\hline \multirow[t]{6}{*}{ Interest } & TRS & & 0.0019 & & 0.0010 & & & 0.0012 \\
\hline & & & $(0.0031)$ & & $(0.0017)$ & & & $(0.0024)$ \\
\hline & $\mathrm{CNGO/PS}$ & & $-0.0010^{\star *}$ & & $-0.0006^{\star *}$ & & $-0.0004^{\star}$ & \\
\hline & & & $(0.0004)$ & & $(0.0002)$ & & $(0.0002)$ & \\
\hline & TRS + CNGO/PS & $\begin{array}{r}-0.0009^{*} \\
(0.0004)\end{array}$ & & $\begin{array}{c}0.0006 \\
(0.0003)\end{array}$ & & $\begin{array}{r}-0.0003^{*} \\
(0.0002)\end{array}$ & & \\
\hline & Year & $\begin{array}{r}-36.1640^{*} \\
(17.9664)\end{array}$ & $\begin{array}{r}-37.9249^{*} \\
(17.3563)\end{array}$ & $\begin{array}{r}-19.8882 \\
(13.7240)\end{array}$ & $\begin{array}{r}-19.9663^{*} \\
(9.6345)\end{array}$ & $\begin{array}{r}-9.6166 \\
(7.5716)\end{array}$ & $\begin{array}{c}-9.5261 \\
(7.2887)\end{array}$ & $\begin{array}{r}-14.7559 \\
(9.2987)\end{array}$ \\
\hline \multirow[t]{2}{*}{ Interest lags } & Wngo & & & & & & $\begin{array}{r}-0.0006 \\
(0.0007)\end{array}$ & \\
\hline & Wtotal & & & $\begin{array}{r}-0.0010 \\
(0.0012)\end{array}$ & & $\begin{array}{r}-0.0006 \\
(0.0007)\end{array}$ & & $\begin{array}{c}0.0003 \\
(0.0007)\end{array}$ \\
\hline \multirow[t]{3}{*}{ Control } & Population density & $\begin{array}{c}1.6356 \\
(0.7531)\end{array}$ & $\begin{array}{r}1.6239^{*} \\
(0.7537)\end{array}$ & $\begin{array}{c}0.9310 \\
(0.6561)\end{array}$ & $\begin{array}{r}0.9502^{*} \\
(0.4328)\end{array}$ & $\begin{array}{c}0.5419 \\
(0.3703)\end{array}$ & $\begin{array}{c}0.5337 \\
(0.3650)\end{array}$ & $\begin{array}{c}0.5060 \\
(0.4089)\end{array}$ \\
\hline & Area within Park & $\begin{array}{l}40.0796^{* * *} \\
(11.776)\end{array}$ & $\begin{array}{l}39.6474^{* * *} \\
(11.7977)\end{array}$ & $\begin{array}{l}43.8096^{\star * \star} \\
(6.2149)\end{array}$ & $\begin{array}{l}23.0481^{* * *} \\
(6.8052)\end{array}$ & $\begin{array}{l}25.3625^{\star * *} \\
(3.5266)\end{array}$ & $\begin{array}{l}25.3063^{* * *} \\
(3.5212)\end{array}$ & $\begin{array}{l}25.1957^{\star * *} \\
(3.7759)\end{array}$ \\
\hline & Precipitation & $\begin{array}{l}10.7847^{\star *} \\
(4.2613)\end{array}$ & $\begin{array}{c}-10.4858^{\star *} \\
(4.3497)\end{array}$ & $\begin{array}{c}1.7246 \\
(3.4910)\end{array}$ & $\begin{array}{c}-6.2238^{* *} \\
(2.5281)\end{array}$ & $\begin{array}{c}0.6480 \\
(1.9545)\end{array}$ & $\begin{array}{c}0.7269 \\
(1.9474)\end{array}$ & $\begin{array}{c}1.0038 \\
(2.0642)\end{array}$ \\
\hline \multirow[t]{3}{*}{ Control lags } & Wpopdens & & & $\begin{array}{l}2.3121^{* * *} \\
(0.7201)\end{array}$ & & $\begin{array}{l}1.3379^{* *} \\
(0.4077)\end{array}$ & $\begin{array}{l}1.3436^{* * *} \\
(0.4097)\end{array}$ & $\begin{array}{l}1.5872^{* * *} \\
(0.4587)\end{array}$ \\
\hline & Wprecip & & & $\begin{array}{r}-28.5078^{*} \\
(13.3857)\end{array}$ & & $\begin{array}{r}-16.0157^{*} \\
(7.4130)\end{array}$ & $\begin{array}{r}-15.9451^{*} \\
(7.8211)\end{array}$ & $\begin{array}{l}-26.3127^{* * *} \\
(7.3953)\end{array}$ \\
\hline & $R^{2}$ & 0.3822 & 0.3869 & 0.5589 & 0.3791 & 0.5455 & 0.5469 & 0.5379 \\
\hline
\end{tabular}

${ }^{1}$ TRS, tourism revenue sharing; CNGO/PS, conservation NGO and private sector funding; Wngo, spatial lag of CNGO/PS; Wtotal, spatial lag of total investments; Wpopdens, spatial lag of population density; Wprecip, spatial lag of precipitation.

${ }^{*} \mathrm{P}<0.1,{ }^{* * \mathrm{P}}<0.05,{ }^{* * * \mathrm{P}}<0.01$. 
TABLE 3 Results of site-demeaned fixed effects regression, with illegal activities as the response variable (Equation 6). Values are regression coefficients with cluster-robust standard errors in parentheses. Column 1 presents the results with raw illegal activities as the response variable, and columns 2-4 are using the illegal activities corrected using catch per unit effort (CPUE). Different specifications are presented isolating tourism revenue sharing and conservation NGO and private sector funding as explanatory variables. Columns 1 and 2 present total investment effect without the population density and precipitation controls, although they differ in that column 1 uses the raw, uncorrected illegal activities as the response whereas column 2 uses the CPUE-corrected variable for comparative purposes. Columns 3 and 4 include the controls but isolate total investments and tourism revenue sharing alone, respectively. A Hausman test was used to select fixed effects over random effects $(\mathrm{P}=0.004)$. For each year there is one aggregated observation for each sector (12 per year). Thus for 10 years, $12 \times 10=120$. With the removal of $2009,120-12=108$. Therefore, the panel constructed has $\mathrm{n}=108$ observations.

\begin{tabular}{|c|c|c|c|c|}
\hline \multirow[b]{2}{*}{ Variable description $^{1}$} & \multirow{2}{*}{$\begin{array}{l}\text { Response variable: } \\
\text { uncorrected, raw illegal activities } \\
1\end{array}$} & \multicolumn{3}{|c|}{$\begin{array}{l}\text { Response variable: } \\
\text { CPUE-corrected illegal activities }\end{array}$} \\
\hline & & 2 & 3 & 4 \\
\hline TRS & & & & $\begin{array}{c}0.0017 \\
(0.0027)\end{array}$ \\
\hline $\mathrm{TRS}+\mathrm{CNGO} / \mathrm{PS}$ & $\begin{array}{r}-0.0007^{\star} \\
(0.0004)\end{array}$ & $\begin{array}{r}-0.0004^{\star} \\
(0.0002)\end{array}$ & $\begin{array}{r}-0.0003^{\star} \\
(0.0002)\end{array}$ & \\
\hline Year & $\begin{array}{r}-12.6876^{*} \\
(6.1323)\end{array}$ & $\begin{array}{c}5.0213 \\
(3.2224)\end{array}$ & $\begin{array}{r}-12.5429 \\
(10.0277)\end{array}$ & $\begin{array}{r}-18.6211 \\
(13.8198)\end{array}$ \\
\hline Population density & & & $\begin{array}{c}0.8113 \\
(0.4919)\end{array}$ & $\begin{array}{c}0.9140 \\
(0.6241)\end{array}$ \\
\hline Precipitation & & & $\begin{array}{c}1.9227 \\
(2.2183)\end{array}$ & $\begin{array}{c}2.1887 \\
(2.2983)\end{array}$ \\
\hline$R^{2}$ & 0.5637 & 0.5904 & 0.6043 & 0.6031 \\
\hline
\end{tabular}

${ }^{1} \mathrm{TRS}$, tourism revenue sharing; CNGO/PS, conservation NGOs and private sector funding.

${ }^{\star} \mathrm{P}<0.1,{ }^{\star *} \mathrm{P}<0.05,{ }^{* *} \mathrm{P}<0.01$. Robust standard errors in parentheses (clustered to sector).

illustrated in the 2012-2015 maps in Fig. 3 and the bivariate spatial association maps in Supplementary Fig. 4, the southwest sectors bordering Volcanoes National Park comprise a neighbourhood of high unauthorized resource use but often receive low funding from tourism revenue sharing, leading to high-low and low-high spatial association areas. This is perhaps one reason why revenue sharing funding did not have a statistically significant effect in reducing illegal activities. In contrast (Fig. 4), conservation NGO investment during 20112015 was largely targeted towards Kabatwa and Gahunga/ Rugarama, areas where there is significant unauthorized resource use. Perhaps the targeting of conservation NGO and private sector funding has been slightly more effective in reducing unauthorized resource use than that of revenue sharing, which is spatially dispersed (Supplementary Fig. 5) and not always directed to neighbourhoods of high unauthorized resource use.

These findings provide new insight into the socioeconomic dimensions of conservation. Although the literature is optimistic about the theoretical promise of integrated conservation-development projects, our findings align with studies that have identified mixed results, particularly of tourism revenue sharing, in practice (Newmark \& Hough, 2000; Barrett et al., 2006; Garnett et al., 2007). Several studies have examined the impact of tourism revenue sharing in the Greater Virunga Landscape, particularly in Uganda (Archabald \& Naughton-Treves, 2001; Adams \& Infield, 2003; Ahebwa et al., 2012; Tumusiime \& Vedeld, 2012;
Mukanjari et al., 2013). In Rwanda, Sabuhoro et al. (2017) and Munanura et al. $(2016,2017)$ focused on local perceptions of revenue sharing around Volcanoes National Park. These studies found limitations to revenue sharing in eliciting community support for conservation, with political influence in decision-making negatively affecting community buy-in (Twinamatsiko et al., 2014; Munanura et al., 2016, 2017; Sabuhoro et al., 2017).

By integrating qualitative GIS into the research design, we have shed light on prioritization of sectors by conservation NGOs and decision makers, providing additional insight into the negative effect of conservation NGO funding on illegal activities, in contrast to tourism revenue sharing (Knigge \& Cope, 2009). We found that the sector of origin of poachers is a high priority. Although the sample size was small $(n=11)$, interviewee responses and subsequent mapping (Fig. 5) suggest that sector of poacher origin was a more important driver of investment than the unauthorized activities themselves. However, conservation NGO and private sector individuals interviewed also perceived their interventions to be filling gaps in tourism revenue sharing, which is subject to bureaucratic and often inefficient project selection processes. Overall, these findings align with those of Munanura et al. (2016): competing interests and priorities may prevent tourism revenue sharing projects from being targeted to the areas where funding could leverage the highest impact. We found that conservation NGOs have more flexibility to fill gaps 

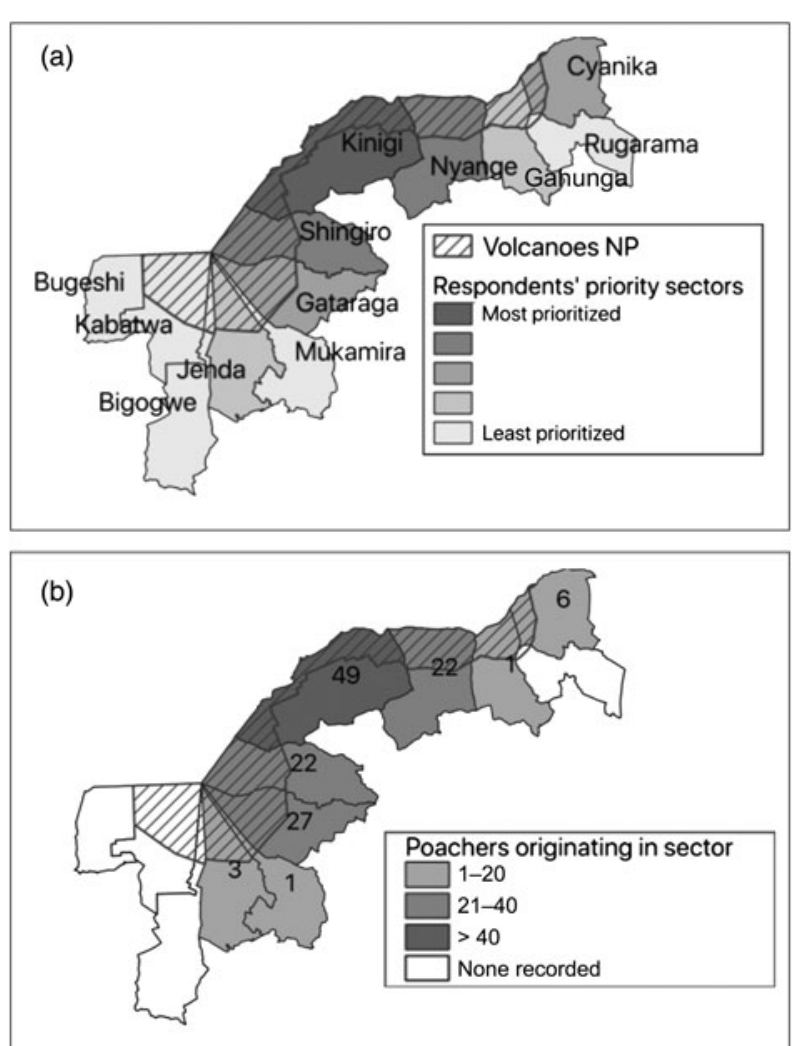

FIG. 5 (a) A ranking of sectors for investment priority based on how the respondents decide where to invest funding for projects (an output of the qualitative GIS interviews). The visualization presents average investment prioritization ranking for each sector across all respondents. Interviewees were asked to rank the top five sectors for integrated conservation-development projects based on their organizational mandate and perception of problem areas. (b) Total number of poachers apprehended by sector during 2011-2015; darker shading indicates more poachers apprehended (data: Law Enforcement Warden, Volcanoes National Park, pers. comm., 2018).

when targeting interventions $\left(\mathrm{NGO}_{3}\right.$; Supplementary Table 3).

Without the mixed-methods research design incorporating qualitative GIS, the conclusions drawn in this study would have been different; this provides a methodological contribution. The hotspot and regression analysis identified spatial and temporal trends that require attention in future project interventions, particularly in the south-west sectors, but that analysis alone would have painted an incomplete picture. This does suggest, however, that sectors of poacher origin may be overprioritized. It may be more effective to consider sectors that experience high levels of needs-based illegal activities such as water collection and fuelwood harvesting, as have been identified in the south-west sectors by the spatial analysis.

In summary, this study has used spatial econometrics techniques, supplemented with qualitative GIS, to link community development investment to incidents of unauthorized resource use in Volcanoes National Park, Rwanda. We used kernel density estimation and bivariate local indicators of spatial association to examine the distribution of tourism revenue sharing and integrated conservation-development project investment by conservation NGOs relative to unauthorized resource use; this was followed by spatial lag of $x$ and fixed-effects regression. Spatial analysis identified gaps in revenue sharing investment relative to clusters of unauthorized resource use, which may partially explain the econometric finding that, unlike conservation $\mathrm{NGO}$ /private sector investment, revenue sharing has not had a significant effect on unauthorized resource use. Qualitative GIS interviews enriched these results with findings that decision makers' priorities and bureaucratic, oftencompeting interests are important underlying drivers of the spatial distribution of tourism revenue sharing investment.

We conclude that the small but significant negative effect of total integrated conservation-development project investment on unauthorized resource use provides evidence that integrated conservation-development projects may be having beneficial impacts in terms of reducing incidents of needs-based illegal activities in the Park over time, despite differences in investment sources. The differences in spatial prioritization between investment sources highlight areas for improvement in revenue sharing. Broadly, this study emphasizes the importance of spatial dynamics in understanding the effect of integrated conservation-development projects on unauthorized resource use over time, particularly for conservation practitioners.

Future studies should spatially link community perceptions and incomes with data from this study to pinpoint how changing perceptions ultimately influence actual behaviours. We also recommend the establishment of a central database of ranger monitoring data alongside socio-economic data and development interventions in the Greater Virunga Transboundary Landscape. Data driven decision-making based on a collective understanding of spatial dynamics could improve the impact of integrated conservation-development projects on unauthorized resource use and ongoing conservation challenges.

Acknowledgements We thank the University of Rwanda, Rwanda National Council for Science and Technology, Rwanda Development Board, the wardens of Volcanoes National Park, and the International Gorilla Conservation Programme. This research received no specific grant from any funding agency, or commercial or not-forprofit sectors.

Author contributions Study design: KPB, TELS, EN; data collection and fieldwork: KPB, ES, IEM; GIS and data analyses, writing: KPB; revisions: all authors.

\section{Conflicts of interest None.}

Ethical standards This research abided by the Oryx guidelines on ethical standards. We acquired affiliation with University of 
Rwanda (DVC-AAR 073/2018), approval from Rwanda Development Board, and clearance from Rwanda National Council for Science and Technology (No. NCST/482/21/2018).

\section{References}

Adams, W.M. \& INField, M. (2003) Who is on the gorilla's payroll? Claims on tourist revenue from a Ugandan National Park. World Development, 31, 177-190.

Addison, P.F., RumpfF, L., Bau, S.S., Carey, J.M., Chee, Y.E., Jarrad, F.C. et al. (2013) Practical solutions for making models indispensable in conservation decision-making. Diversity and Distributions, 19, 490-502.

Adiya, B., Vanneste, D., van Rompaey, A. \& Ahebewa, W.M. (2014) Spatial analysis of tourism income distribution in the accommodation sector in western Uganda. Tourism and Hospitality Research, 14, 8-26.

Ahebwa, W.M., van der Duim, R. \& Sandbrook, C. (2012) Tourism revenue sharing policy at Bwindi Impenetrable National Park, Uganda: a policy arrangements approach. Journal of Sustainable Tourism, 20, 377-394.

Albers, H.J. (2010) Spatial modeling of extraction and enforcement in developing country protected areas. Resource and Energy Economics, 32, 165-179.

Anselin, L. (1988) Spatial Econometrics: Methods and Models. Kluwer, Dordrecht, The Netherlands.

Anselin, L. (2018) Global Spatial Autocorrelation: Bivariate, Differential and EB Rate Moran Scatter Plot. geodacenter.github.io/ workbook/5b_global_adv/lab5b.html [accessed January 2018].

Archabald, K. \& Naughton-Treves, L. (2001) Tourism revenue-sharing around national parks in Western Uganda: early efforts to identify and reward local communities. Environmental Conservation, 28, 135-149.

Barrett, C.B., Gibson, C.C., Hoffman, B. \& McCubiins, M.D. (2006) The complex links between governance and biodiversity. Conservation Biology, 20, 1358-1366.

Beale, C.M., Brewer, M.J. \& Lennon, J.J. (2014) A new statistical framework for the quantification of covariate associations with species distributions. Methods in Ecology and Evolution, 5, 421-432.

Briant, A., Combes, P.P. \& Lafourcade, M. (2010) Dots to boxes: Do the size and shape of spatial units jeopardize economic geography estimations? Journal of Urban Economics, 67, 287-302.

Critchlow, R., Plumptre, A.J., Alidria, B., Nsubuga, M., Driciru, M., Rwetsib A, A. et al. (2017) Improving law-enforcement effectiveness and efficiency in protected areas using ranger-collected monitoring data. Conservation Letters, 10, 572-580.

GADM (2018) Database of Global Administrative Areas. Administrative boundaries, Rwanda, Uganda, Democratic Republic of the Congo. Center for Spatial Sciences, University of California, Davis, USA.

Garnett, S.T., SAyer, J. \& Du Toit, J. (2007) Improving the effectiveness of interventions to balance conservation and development: a conceptual framework. Ecology and Society, 12, 2.

Goodman, S., BenYishay, A., Lv, Z. \& Runfola, D. (2019) GeoQuery: integrating HPC systems and public web-based geospatial data tools. Computers \& Geosciences, 122, 103-112.

Gibions, S. \& Overman, H.G. (2012) Mostly pointless spatial econometrics? Journal of Regional Science, 52, 172-191.

Hilborn, R., Arcese, P., Borner, M., Hando, J., Hopcraft, G., Lогвоокі, M. et al. (2006) Effective enforcement in a conservation area. Science, 314, 1266.

Honey, M. (1999) Ecotourism and Sustainable Development: Who Owns Paradise? Island Press, Washington, DC, USA.
Hsiang, S. \& Sekar, N. (2016) Does Legalization Reduce Black Market Activity? Evidence from a Global Ivory Experiment and Elephant Poaching Data. National Bureau of Economic Research (No. w22314), Cambridge, USA.

Keane, A., Jones, J.P.G. \& Milner-Gulland, E.J. (2011) Encounter data in resource management and ecology: pitfalls and possibilities. Journal of Applied Ecology, 48, 1164-1173.

Knigge, L. \& Cope, M. (2009) Grounded visualization and scale: a recursive analysis of community spaces. In Qualitative GIS: A Mixed Methods Approach (eds M. Cope \& S. Elwood), pp. 95-114. Sage Publications, London, UK.

LEE, S.I. (2001) Developing a bivariate spatial association measure: an integration of Pearson's $r$ and Moran's I. Journal of Geographical Systems, 3, 369-385.

Mackenzie, C.A., Chapman, C.A. \& Sengupta, R. (2011) Spatial patterns of illegal resource extraction in Kibale National Park, Uganda. Environmental Conservation, 39, 38-50.

Maekwa, M., Lanjouw, A., Rutagarama, E. \& Sharp, D. (2015) Mountain gorilla ecotourism: supporting economic growth and providing local livelihoods. In Livelihoods, Natural Resources, and Post-Conflict Peacebuilding (eds H. Young \& L. Goldman), p. 167. Routledge, London, UK.

Martin, A., Rutagarama, E., Cascão, A., Gray, M. \& Chhotray, $\mathrm{V}$. (2011) Understanding the co-existence of conflict and cooperation: transboundary ecosystem management in the Virunga Massif. Journal of Peace Research, 48, 621-635.

Moore, J.F., Mulindahabi, F., Masozera, M.K., Nichols, J.D., Hines, J.E., Turikunkiko, E. \& Oli, M.K. (2018) Are ranger patrols effective in reducing poaching-related threats within protected areas? Journal of Applied Ecology, 55, 99-107.

Moulton, B.R. (1990) An illustration of a pitfall in estimating the effects of aggregate variables on micro units. The Review of Economics and Statistics, 72, 334-338.

Mukanjari, S., Bednar-Friedl, B., Muchapondwa, E. \& Zikhali, P. (2013) Evaluation the prospects of benefit sharing schemes in protecting mountain gorillas in Central Africa. Natural Resource Modeling, 26, 455-479.

Munanura, I.E. (2013) The household poverty dimensions influencing forest dependence in protected area neighboring communities in Africa and the mitigation potential of tourism: the case of Volcanoes National Park, Rwanda. PhD thesis. Clemson University, Clemson, USA.

Munanura, I.E., Backman, K.F., Hallo, J.C. \& Powell, R.B. (2016) Perceptions of tourism revenue sharing impacts on Volcanoes National Park, Rwanda: a sustainable livelihoods framework. Journal of Sustainable Tourism, 24, 709-726.

Munanura, I.E., Backman, K.F., Sabuhoro, E., Powell, R.B. \& Hallo, J.C. (2017) The perceived forms and drivers of forest dependence at Volcanoes National Park, Rwanda. Environmental Sociology, 4, 343-357.

Newmark, W.D. \& Hough, J.L. (200o) Conserving wildlife in Africa: integrated conservation and development projects and beyond. BioScience, 50, 585-592.

Nielsen, H. \& Spenceley, A. (2011) The success of tourism in Rwanda: gorillas and more. In Yes, African Can: Success Stories from a Dynamic Continent. Chapter 14, pp. 231-249. World Bank Publications, Washington, DC, USA.

NISR (2017) 'District Profile: Musanze'. National Institute of Statistics of Rwanda, Ministry of Finance and Economic Planning (MINECOFIN) Rwanda, 2012. Rwanda Fourth Population and Housing Census, Kigali, Rwanda.

ORTPN (2005) Tourism Revenue Sharing in Rwanda: Policy and Guidelines. Rwanda Wildlife Agency, Rwanda Office of Tourism and National Parks, Kigali, Rwanda. 
Plumptre, A.J., Kayitare, A., Rainer, H., Gray, M., Munanura, I., Barakabuye, N. et al. (2004) The Socio-Economic Status of People Living Near Protected Areas in the Central Albertine Rift. Wildlife Conservation Society, New York, USA.

Plumptre, A.J., Fuller, R.A., Rwetsiba, A., Wanyama, F., Kujirakwinja, D., Driciru, M. et al. (2014) Efficiently targeting resources to deter illegal activities in protected areas. Journal of Applied Ecology, 51, 714-725.

RAINER, H. (2013) The political ecology and economy of protected areas and violence: a case study of the conflict of the Kivus in the Democratic Republic of Congo. PhD thesis. The London School of Economics and Political Science, London, UK.

Sabuhoro, E., Wright, B., Munanura, I.E., Nyakabwa, I.N. \& Nibigira, C. (2017) The potential of ecotourism opportunities to generate support for mountain gorilla conservation among local communities neighboring Volcanoes National Park in Rwanda. Journal of Ecotourism, published online 25 January 2017.

Silverman, B.W. (1986) Density Estimation for Statistics and Data Analysis. Chapman and Hall, New York, USA.

Stock, J. \& Watson, M. (2006) Heteroskedasticity-Robust Standard Errors for Fixed Effects Panel Data Regression. NBER Technical
Working Paper 323. National Bureau of Economic Research, Cambridge, USA.

Taylor, F.E., Millington, J.D., Jacob, E., Malamud, B.D. \& Pelling, M. (2020) Messy maps: qualitative GIS representations of resilience. Landscape and Urban Planning, 198, 103771.

Tumusime, D.M. \& Vedeld, P. (2012) False promise or false premise? Using tourism revenue sharing to promote conservation and poverty reduction in Uganda. Conservation and Society, 10, 15-28.

Twinamatsiko, M., Baker, J., Harrison, M., Shirkhorshidi, M., Bitariho, R., Wieland, M. et al. (2014) Linking Conservation, Equity and Poverty Alleviation: Understanding Profiles and Motivations of Resource Users and Local Perceptions of Governance at Bwindi Impenetrable National Park, Uganda. IIED Research Report, London, UK.

UNEP-WCMC (2014) World Database on Protected Areas. United Nations Environment Programme-World Conservation Monitoring Centre, Cambridge, UK. protectedplanet.net [accessed July 2018].

Watson, F., Becker, M.S., McRobi, R. \& Kanyembo, B. (2013) Spatial patterns of wire-snare poaching: implications for community conservation in buffer zones around National Parks. Biological Conservation, 168, 1-9. 